assess which of the markets will maximize their revenue," says analyst Amber Gibson, author of the report. "Companies should also establish strong relationships with governments and ensure that the vaccines they are developing are in line with government priorities," she adds.

A cost-effectiveness analysis of the Lyme disease vaccine by the CDC indicates that the use of LYMErix vaccine is justified only in areas in which the inci- $\begin{gathered}\text { Meningitis } \\ \mathbf{1 2 . 8 \%}\end{gathered}$ dence of Lyme disease is high. They found that the mean net savings of vaccination per case averted is $\$ 3,377$ if the probability of contracting Lyme
Disease breakdown of the global vaccines market (2001). Source: Datamonitor
He says, "This vaccine was developed because of a perceived demand by the public for protection against a common infection," but he remembers that the CDC gave the vaccine at best a "lukewarm" recommendation. They proposed disease is estimated at 0.03 . However, the probability of contracting Lyme disease is, in all but a few areas, less than 0.005 .

Vaccine expert Stanley Plotkin, who presently consults for Aventis Pasteur, calls the withdrawal of LYMErix "regrettable."

\section{Tech transfer pays off}

Technology transfer is starting to pay off for North America's universities and hospitals according to a new survey released by the Association of University Technology Managers (AUTM). After five years of annual growth at a rate of $20 \%$, income from license agreements jumped to $47 \%$, amounting to $\$ 1.26$ billion, for the last fiscal year analyzed, which was 2000.

"Some of it is simply a maturation of the [biotech] industry," says AUTM president-elect Patricia Harsche, of Fox Chase Cancer Center in Philadelphia. "Many of the licenses that were entered into eight to ten years ago are now products."

Several one-time events, however, have inflated the total figure. The biggest-\$200 million-was the University of California's settlement of two patent infringement lawsuits against biotech company Genentech for human growth hormone. But even without that settlement, license income across the board for these institutions grew 23\%

with most of the money coming in the form of product royalties.

Several institutions earned more than $\$ 30$ million in royalties, and two-the
University of California and Columbiatopped \$100 million. Queen's University in Kingston, Ontario, whose royalty payments came to $\$ 5.4$ million (up $800 \%$ on the previous year) can thank the Food and Drug Administration's approval of Levulan, a photodynamic therapy system for precancerous skin lesions, and European sales of erectile dysfunction drug Uprima contributed, as well as unspecified royalties from Bristol-Myers Squibb for patents on the cancer drug Taxol.

Income from redeemed ownership of never reach the market. "No company is going to spend hundreds of millions to develop a vaccine that will not be recommended and therefore will not sell," he points out.

But these new vaccines are making their way through the academic research pipeline nonetheless, including a combined vaccine against WNV and dengue virus (Proc. Natl. Acad. Sci. USA 99, 3036; 2002). The Datamonitor report indicates that WNV vaccines are unlikely to be strong candidates for widespread immunization programs. "However, the susceptibility of infants and the over-50s to the more severe manifestations of this disease mean that in endemic regions vaccines could be considered for both childhood and elderly immunization programs," they point out.

Gibson suggests that development of novel technologies in vaccine discovery, formulation and delivery will be critical for attaining market share. When assessing the value of a vaccine, various factors, such as the severity of the disease and the mortality rate, must be considered, but so must the cost of treating the disease. "Basically, if the cost of immunizing every individual is lower than the cost of treating the number who get the disease, then you can justify its use," she says.

\section{Emma Hitt, Atlanta}

Increase in tech transfer deals for US and Canadian academic institutions and hospitals
\begin{tabular}{|l|c|c|c|c|}
\hline & 1997 & 1998 & 1999 & 2000 \\
\hline $\begin{array}{l}\text { Adjusted gross license } \\
\text { income (millions) }\end{array}$ & 611 & 725 & 862 & 1,263 \\
\hline Invention disclosures & 11,303 & 11,784 & 12,324 & 13,032 \\
\hline $\begin{array}{l}\text { Patent applications } \\
\text { filed }\end{array}$ & 6,629 & 7,714 & 8,802 & 9,925 \\
\hline Start-ups formed & 333 & 364 & 344 & 454 \\
\hline
\end{tabular}

Source: Association of University Technology Managers Licensing Survey: FY 2000

shares in companies rose from $\$ 25$ million to $\$ 165$ million, or $15 \%$ of total income. For example, Dartmouth College sold $\$ 60$ million in equity from the monoclonal antibody company Medarex, which was cofounded in 1987 by Dartmouth Medical School; and Georgetown University received \$26 million for Aventis' allergy drug Allegra which was invented by Georgetown's Raymond Woosley.

2000 also saw a $32 \%$ increase in the number of academic startup companies, a trend that's likely to continue, says Mark Chalek, director of the office of corporate research at Boston's Beth Israel Deaconness Medical Center, which tripled its income in 2000. "People have realized you can do these things thoughtfully, deal with the conflicts of interest, and create firewalls between companies and academic labs appropriately," he says. 